\title{
Eerste Evaluatie van de Jeugdwet: transformatie in zicht?
}

\author{
Freek Bucx · Janke de Groot · Rutger Hageraats · Tarik Pehlivan
}

Published online: 13 November 2018

(C) Bohn Stafleu van Loghum is een imprint van Springer Media B.V., onderdeel van Springer Nature 2018

\begin{abstract}
Samenvatting Sinds 2015 is de Jeugdwet van kracht, waarin de verantwoordelijkheid voor de jeugdhulp bij de gemeente is komen te liggen. Deze wet bevat twee soorten doelen. Ten eerste doelen die de kwaliteit van de jeugdhulp, en de veiligheid en de rechtspositie van cliënten waarborgen. Ten tweede doelen die een transformatie beogen waarin er eerder hulp op maat wordt gegeven, en er meer samenhang is en meer ruimte voor professionals. In de Eerste Evaluatie van de Jeugdwet werd onderzocht hoe het drie jaar na de invoering staat met de realisatie van deze doelen - onder andere via onderzoeken naar de perspectieven van cliënten, gemeenten en het zorglandschap, en een juridische analyse. In dit artikel geven we de belangrijkste bevindingen weer. Algemene conclusie is dat de uitvoering van de Jeugdwet zich op een aantal belangrijke punten (nog) niet in de richting van de doelen van de Jeugdwet beweegt. Zo is het lang niet altijd eenvoudig voor cliënten om hulp te krijgen, en is er (nog) geen vermindering van specialistische jeugdhulp waarneembaar. Ook komt de samenwerking tussen jeugdhulpaanbieders onderling, en met het bredere sociale domein lang niet altijd van de grond. We doen enkele aanbevelingen, onder andere om de vindbaarheid van hulp te vergroten.
\end{abstract}

De auteurs worden in alfabetische volgorde vermeld.

\section{F. Bucx $(\square)$}

Sociaal en Cultureel Planbureau (SCP), Den Haag,

Nederland

f.bucx@scp.nl

J. de Groot

Nivel, Utrecht, Nederland

R. Hageraats

Nederlands Jeugd Instituut, Utrecht, Nederland

T. Pehlivan

Stichting Alexander, Amsterdam, Nederland
Trefwoorden Jeugdwet · jeugdhulp • sociaal domein . transformatie

Abstract The Dutch Child and Youth Act has been in force since 2015, in which responsibilities for youth care were transferred to municipalities. The legislation contains two kinds of aims. Firstly, the aims for safeguarding the quality of youth care, and the safety and legal status of clients. And secondly, aims with the intention of bringing about a transformation in youth care in that made to measure assistance is offered, and that there is more coherence and space for professionals to operate in. The first evaluation of the legislation entailed an analysis of the status of these aims, including studies into the perspectives of clients, municipalities and the care system. In this article we report on the most significant findings. The general conclusion is that with regard to a number of important aspects, the execution of the legislation is not (yet) moving in the direction of the aims in mind when it was created. For example, it is not always easy for clients to gain access to assistance, and there is (still) no visible reduction in specialist youth care. Furthermore, the intended cooperation between youth care providers themselves, and with the wider social domain, has yet to be reached. We have made some recommendations, which will hopefully improve accessibility to the right care.

Keywords Child and Youth act · Youth care - Social domain · Transformation 


\section{Kernpunten}

- In de Eerste Evaluatie van de Jeugdwet is onderzocht hoe het na drie jaar staat met de realisatie van de beoogde doelen - onder andere via onderzoeken onder cliënten, gemeenten en het zorglandschap, en via een juridische analyse.

- De uitvoering van de Jeugdwet beweegt zich op een aantal belangrijke punten (nog) niet in de richting van de doelen van de Jeugdwet.

- Zo is het lang niet altijd eenvoudig voor cliënten om hulp te krijgen en is er (nog) geen vermindering van specialistische jeugdhulp waarneembaar.

- Ook komt de samenwerking tussen jeugdhulpaanbieders onderling en met het bredere sociale domein lang niet altijd van de grond.

\section{Inleiding}

Sinds 1 januari 2015 is de Jeugdwet van kracht, waarin de bestuurlijke en financiële verantwoordelijkheid voor de jeugdhulp bij de gemeenten is komen te liggen [1]. De Jeugdwet beoogt 'het jeugdstelsel te vereenvoudigen en het efficiënter en effectiever te laten maken met het uiteindelijke doel het versterken van de eigen kracht van de jongere en van het zorgend en probleemoplossend vermogen van diens gezin en sociale omgeving' [2]. Om dat te bereiken, is er volgens de overheid een omslag (transformatie) nodig in de hulp aan jeugdigen en gezinnen: met minder dure gespecialiseerde hulp, maar eerder juiste hulp op maat en ook meer samenhang.

\section{De Jeugdwet: waarborg- en transformatiedoelen}

Hoe is het drie jaar na de invoering van de Jeugdwet gesteld met de realisatie van de doelen van de Jeugdwet? Dat is de centrale vraag van dit artikel, dat gebaseerd is op de Eerste Evaluatie van de Jeugdwet [3]. We onderscheiden daarbij drie waarborgdoelen en drie transformatiedoelen. De waarborgdoelen betreffen de vereisten voor de uitvoering van de jeugdhulp. Ten eerste is de gemeente - in lijn met de jeugdhulpplicht (artikel 2.3) - verplicht waarborgen te bieden voor zowel de toegang als het aanbod van de jeugdzorg. Ten tweede zijn er in de wet eisen opgesteld over de kwaliteit van de uitvoering van de hulp, waaronder bijvoorbeeld het gebruik van een hulpverleningsplan. En ten derde bevat de Jeugdwet bepalingen die de rechtspositie van kinderen en hun ouders dienen te waarborgen, bijvoorbeeld bepalingen over de verplichte informatie over de hulp.

In de memorie van toelichting worden vijf transformatiedoelen genoemd. Omdat de eerste drie doelen inhoudelijk sterk met elkaar samenhangen, hebben we deze samengevoegd, en komen we daarmee uit op drie transformatiedoelen. Het eerste doel is dat er minder intensieve hulp nodig is. Aangenomen wordt dat dit mogelijk is wanneer er meer wordt geïnvesteerd in preventie en in het opvoedkundig klimaat in gezinnen, wijken en scholen (de zogenoemde 'pedagogische civil society'), er eerder lichtere vormen van hulp worden aangeboden ('demedicaliseren') en er meer aandacht is voor de eigen mogelijkheden van cliënten. Dan zou namelijk voorkomen kunnen worden dat problematiek verergert en er intensieve, specialistische hulp nodig is. De verwachting was dat de gemeenten een financiële prikkel zouden ervaren om te investeren in lichtere vormen van hulp doordat ze de financiële verantwoordelijkheid kregen voor (nagenoeg) het gehele jeugdterrein.

Het tweede transformatiedoel is meer samenhang, bijvoorbeeld via een meer integrale aanpak in het gezin en meer samenwerking. De verwachting was dat gemeenten, beter dan de landelijke en provinciale overheid, in staat zijn de hulp af te stemmen op de lokale situatie en om 'domeinoverstijgend' te werken.

Het derde en laatste transformatiedoel was dat zorgaanbieders en hulpverleners meer ruimte krijgen. De verwachting is dat de Jeugdwet hiervoor kan zorgen doordat de regeldruk wordt verminderd.

\section{De rol van gemeenten, het zorglandschap én cliënten in de Jeugdwet}

Het belangrijkste instrument in de Jeugdwet is de decentralisatie van de verantwoordelijkheid voor het bieden van jeugdhulp, kinderbeschermingsmaatregelen en jeugdreclassering, en daarmee alle uiteenlopende financieringsstromen, naar één partij: de gemeente. Dit zou de gemeente in staat stellen om de organisatie van de algemene jeugdvoorzieningen, de preventie, de jeugdgezondheidszorg en de jeugdhulp op een effectieve manier in samenhang aan te sturen. Van het zorglandschap wordt verwacht dat het op een andere manier hulp en ondersteuning gaat bieden: minder specialistisch, meer gericht op samenwerking en minder gericht op medicalisering van problemen. En ook cliënten, de 'eindgebruikers', krijgen een nieuwe rol. Zij worden aangesproken op zowel het inzetten van de 'eigen kracht' en 'eigen regie' in het kader van hun hulpvraag, als het uitoefenen van medezeggenschap ten aanzien van het lokale beleid van de jeugdhulp. De rollen van deze drie partijen - gemeenten, het zorglandschap en cliënten - en hun perspectief staan centraal in dit onderzoek.

\section{Onderzoeksmethoden}

Voor deze evaluatie zijn vier deelonderzoeken uitgevoerd. Naast een onderzoek naar juridische knelpunten van de Jeugdwet zijn drie afzonderlijke onderzoeken uitgevoerd naar de perspectieven van gemeenten, het zorglandschap en cliënten. Er is gebruikgemaakt van verschillende externe bronnen, zoals Kamerstuk- 
ken, gegevens van het Centraal Bureau voor de Statistiek (CBS), (beleids)rapportages en onderzoeken, en publicaties in de media. Tevens zijn er nieuwe gegevens verzameld: onder gemeenten, het zorglandschap en cliënten.

Er is onder 235 gemeenten een enquête gehouden; de respons was $71 \%$. Daarnaast vond er een analyse plaats van gemeentelijke beleidsdocumenten in combinatie met interviews in twaalf geselecteerde gemeenten, en werden er focusgroepgesprekken met enkele gemeenten gevoerd.

In het zorglandschap is een enquête gehouden onder 47 managers/leidinggevenden en 21 professionals van lokale teams, en onder 108 managers/ leidinggevenden en 52 professionals van gespecialiseerde jeugdhulpaanbieders. De respons varieerde van 8 tot $38 \%$. Daarnaast vond er een focusgroepgesprek plaats met afgevaardigden van branche- en beroepsverenigingen.

Om het perspectief van cliënten in kaart te brengen is er een enquête gehouden onder 938 ouders, met een respons van $19 \%$. Bij het grootste deel van deze gezinnen was er sprake van ambulante jeugdhulp. Daarnaast werden er diepte-interviews met dertig jongeren gevoerd. De meeste jongeren kregen hulp in een leefgroep, gezinshuis of pleeggezin.

Het bleek lastig om ouders en zorgaanbieders voor onze enquêtes te bereiken. De respons stak meestal wel positief af bij de respons van veel vergelijkbare andere onderzoeken, maar was in absolute zin aan de lage kant. Het is aannemelijk dat bepaalde groepen minder goed vertegenwoordigd zijn in ons onderzoek - bijvoorbeeld ouders die meer moeite hebben met de Nederlandse taal, zoals mensen met een migratieachtergrond. Om die reden vormen de respondenten geen dwarsdoorsnede van de populatie - de bevindingen zijn daardoor niet te generaliseren. Wel is het mogelijk om de verbeterpunten van de Jeugdwet te signaleren.

In alle fasen van het onderzoek is door onderzoekers samen met de begeleidingscommissie en een klankbordgroep van cliënten gereflecteerd op de uitkomsten. Voor meer gedetailleerde informatie over de onderzoeksmethoden verwijzen we de lezer naar ons rapport [3].

\section{Resultaten, conclusies en beschouwing}

\section{Algemene conclusie: transformatie nog niet in zicht}

Op basis van ons onderzoek ontstaat het beeld dat er sinds de invoering van de Jeugdwet in 2015 veel is veranderd, en dat komt overeen met eerder onderzoek $[4,5]$. Gemeenten hebben invulling gegeven aan hun nieuwe taken, en hebben dat in het algemeen op een voortvarende manier gedaan: ze hebben personeel aangenomen en activiteiten opgezet, contracten gesloten met jeugdhulpaanbieders en lokale teams opgezet die een cruciale rol hebben gekregen bij het realiseren van de doelen van de Jeugdwet. Al deze veranderingen zijn vooral te kenmerken als transitie.

Anderzijds moet de zogenoemde transformatie grotendeels nog op gang komen: we constateren dat de uitvoering van de Jeugdwet zich op een aantal belangrijke punten (nog) niet beweegt in de richting van de doelen van de Jeugdwet. Het ligt ook niet voor de hand dat deze doelen nu al zijn gerealiseerd; daarvoor zijn de ambities van de Jeugdwet ook te fors. Gemeenten spreken van een lerend systeem: elkaar leren kennen en vertrouwen. Dat kost tijd. Toch verwachten we niet dat deze transformatiedoelen in de nabije toekomst als vanzelf gerealiseerd gaan worden, zonder verdere acties. De betrokken partijen zullen hun aandacht moeten verleggen van transitie naar transformatie.

Hieronder bespreken we de belangrijkste bevindingen in relatie tot de drie waarborgdoelen en de drie transformatiedoelen die we in de inleiding hebben beschreven, en de aannamen en verwachtingen die hierover impliciet of expliciet werden geformuleerd in de Jeugdwet. Op basis hiervan doen we enkele aanbevelingen.

\section{Waarborgdoel 1: toegang en aanbod}

De gemeenten hebben de verplichting gekregen voor een deskundige toegang te zorgen. Door de jeugdhulp 'dichter bij de burger' te brengen, zou de toegang tot de hulp laagdrempeliger worden. Uit ons onderzoek onder ouders en jongeren komt echter naar voren dat het lang niet altijd eenvoudig is om hulp te krijgen. Bijna een op de drie ouders in ons onderzoek vindt bijvoorbeeld dat dat veel moeite heeft gekost. Een ongeveer even groot aandeel van de gemeenten heeft ook de indruk dat cliënten de toegang niet gemakkelijk kunnen vinden. Het verdient daarom aanbeveling om de informatievoorziening door gemeenten over de toegang te intensiveren en indien nodig ook de toegang zelf te verbeteren.

Juist gezinnen in een kwetsbare positie - eenoudergezinnen en gezinnen met een laag inkomen - zijn het meest negatief over de toegang. De ondersteuning van deze gezinnen vraagt om extra en gerichte aandacht van gemeenten en hulpverleners.

\section{Waarborgdoel 2: kwaliteit}

Met de invoering van de nieuwe Jeugdwet werd verwacht dat de kwaliteit van de jeugdhulp zou verbeteren, in lijn met de kwaliteitseisen die de Jeugdwet stelt. Onze onderzoeken geven soms een tegenstrijdig beeld van hoe het met de kwaliteit is gesteld. Zo ervaren de meeste ouders dat aan de kwaliteitseisen die de Jeugdwet aan hulp en hulpverleners stelt grotendeels voldaan wordt, en dat geldt ook voor de gemeenten. De aanbieders van jeugdhulp en de professionals zijn soms veel kritischer. Zij zijn vooral kritisch over de 
middelen die gemeenten bieden om de kwaliteit op peil te houden.

Landelijke cijfers ontbreken - daarom kan er niet systematisch nagegaan worden in hoeverre de kwaliteitseisen worden gerealiseerd. Gemeenten stellen bovendien dat zij met de instrumenten bekostiging en verantwoording, en door het ontbreken van eenduidige informatie over doelrealisatie in hun gemeente, weinig invloed hebben op de kwaliteit. Het lijkt ons daarom verstandig dat er een uniforme set van kwaliteitsindicatoren wordt ontwikkeld. Ook zouden gemeenten kunnen onderzoeken hoe zij hun eigen maatschappelijke doelrealisatie beter kunnen monitoren.

\section{Waarborgdoel 3: de rechtspositie van de cliënt}

De Jeugdwet voorziet in enkele rechtswaarborgen die cliënten invloed moeten geven op de hulp en het beleid. Deze worden echter nog onvoldoende waargemaakt, zo blijkt uit ons onderzoek. Ten aanzien van de hulp met drang constateren we dat er veel onduidelijkheid is over de gevolgen die gegevensuitwisseling tussen instanties heeft voor de rechtspositie van cliënten. Deels komt dat doordat de gekozen waarborgen minder effectief zijn in dit domein: het recht op privacy beperkt gemeenten bijvoorbeeld om domeinoverstijgend te werken. Er moet gezocht worden naar passende oplossingen hiervoor. Daarnaast dienen cliënten nadrukkelijker gewezen te worden op hun recht om bijvoorbeeld vertrouwenspersonen en cliëntondersteuners in te schakelen - de ouders en jongeren in ons onderzoek zijn zich vaak niet bewust van dit recht. Terwijl verreweg de meeste ouders in ons onderzoek - ongeveer negen op de tien - over het algemeen wel ervaren betrokken te worden bij de organisatie van de hulp, hebben de jongeren meer twijfels. Zij noemen als verbeterpunt dat de doelen van de hulp beter in overleg bepaald kunnen worden en dat niet de hulpverlener hierover het laatste woord krijgt.

\section{Transformatiedoel 1: minder intensieve hulp}

Doel was dat er meer geïnvesteerd zou worden in preventie en lichtere vormen van hulp, waardoor er minder behoefte zou zijn aan intensieve, specialistische hulp. De verwachting was dat de gemeenten een financiële prikkel zouden ervaren om dat te doen doordat zij de financiële verantwoordelijkheid voor (nagenoeg) het gehele jeugdterrein hebben gekregen. Bijna acht op de tien ouders in ons onderzoek geven aan dat er in de hulp die het gezin ontvangt, aandacht is voor de mogelijkheden ('eigen kracht') van het gezin. Ook gemeenten zien enkele positieve ontwikkelingen op het gebied van vroegsignalering en het versterken van het opvoedkundig klimaat: bijvoorbeeld in de samenwerking van lokale teams met partijen als maatschappelijk werk, scholen, huisartsen en specialistische hulp.
Desondanks is er (nog) geen vermindering van specialistische jeugdhulp waarneembaar, zo blijkt bijvoorbeeld uit de gegevens van het CBS [6]. Daarvoor lijkt de investering in preventie en de kwaliteit van hulp in de eerste lijn nog te beperkt, aldus professionals en bestuurders in de zorg. Volgens gemeenten speelt daarnaast een rol dat de aandacht voor preventie en vroegsignalering ook juist tot een grotere behoefte leidt aan specialistische jeugdhulp. Wil dit transformatiedoel in de nabije toekomst gerealiseerd worden, dan zouden gemeenten meer dan nu op preventie en hulp in de eerste lijn moeten inzetten.

\section{Transformatiedoel 2: meer samenhang}

Het tweede transformatiedoel is meer samenhang te creëren, onder andere door een meer integrale aanpak in het gezin en grotere samenwerking tussen hulpverleners. De gemeenten in ons onderzoek onderschrijven de meerwaarde van het leggen van verbindingen tussen jeugdhulp en schuldhulpverlening, onderwijs of huisvesting. Zij zien ook daadwerkelijk meer samenwerking tussen jeugdhulpaanbieders onderling, en met het bredere sociale domein, maar tegelijkertijd komt die samenwerking lang niet altijd van de grond. Naarmate er meer hulpverleners in een gezin zijn, zijn ook de ouders en jongeren in ons onderzoek minder positief over de onderlinge afstemming. Niet alleen bij kwetsbare gezinnen, maar ook bij de overgang van achttien-min naar achttien-plus verloopt de hulp niet zonder problemen, aldus alle partijen: de jongeren geven aan dat zij onvoldoende op deze overgang worden voorbereid.

Het domeinoverstijgend werken wordt onder andere belemmerd door de juridische procedures die de privacy van cliënten beschermen, maar als ongewenst effect hebben dat zij de gegevensuitwisseling bemoeilijken. Ook de samenwerking tussen hulpverleners wordt bemoeilijkt door het juridische instrumentarium: het aanbestedingsinstrument - het instrument van gemeenten om hulp in te kopen - laat aanbieders van jeugdhulp namelijk met elkaar concurreren. Het verdient daarom aanbeveling te onderzoeken hoe deze instrumenten en/of alternatieve procedures ingezet kunnen worden zonder dat dergelijke ongewenste effecten optreden.

\section{Transformatiedoel 3: meer ruimte voor professionals}

Het derde doel was dat zorgaanbieders en hulpverleners meer ruimte krijgen om hun werk zodanig in te richten dat ze passende zorg leveren. De verwachting was dat zij door de Jeugdwet hiertoe in staat zouden worden gesteld, en dat zij dat ook zouden willen. Uit ons onderzoek komt naar voren dat de verschillende partijen zeggen achter deze doelen van de Jeugdwet te staan. Tegelijkertijd worden bij de uitvoering diverse knelpunten ervaren. Zo komt uit de interviews met professionals naar voren dat de 
ruimte voor de professionals beperkt wordt door de ruimte die elke gemeente heeft om een eigen verantwoordings- en administratief systeem te hanteren. Dit heeft volgens hen op lokaal niveau geleid tot een diversiteit aan organisatievormen en verantwoordingseisen, waardoor professionals veel tijd kwijt zijn aan administratie. Volgens gemeenten wordt daarnaast de ruimte die er wel is, ook niet altijd door de professionals benut. Zowel gemeenten als zorgaanbieders zouden meer kunnen doen om dergelijke belemmeringen, werkelijke dan wel veronderstelde, weg te nemen. Een andere reden waarom dit derde doel nog niet wordt verwezenlijkt is dat er geen gedeelde visie is over wat in welke situatie passende zorg is. Een constructief debat hierover tussen cliënten, gemeenten en zorgverleners zou hieraan kunnen bijdragen.

\section{Hoe verder na de evaluatie?}

De Eerste Evaluatie van de Jeugdwet is op 30 januari 2018 gepubliceerd. Op 16 april 2018 stuurden de ministers De Jonge (VWS) en Dekker (Rechtsbescherming) hun inhoudelijke reactie naar de Tweede Kamer, in de vorm van het Actieprogramma Zorg voor de Jeugd. De ministers hebben bij het actieplan ook andere rapporten betrokken die in deze periode zijn verschenen $^{1}$. Op het moment van schrijven van dit artikel was de uitwerking van de onderdelen van het programma nog gaande.

Hoewel elke partij zo zijn eigen invalshoek en daarmee specifieke opmerkingen heeft over hoe het met de zorg voor de jeugd is gesteld, blijken de conclusies van de eerste evaluatie breed te worden gedeeld. In de media is vooral de constatering aangehaald dat een derde van (in het bijzonder kwetsbare) burgers de weg naar passende hulp nog onvoldoende weet te vinden.

Wij hebben als onderzoekers vooral beoogd het gesprek tussen de gemeenten en veldpartijen te bevorderen over een gezamenlijke agenda om de transformatie verder invulling te geven. Dat lijkt gelukt. Het programma Zorg voor de Jeugd is nadrukkelijk gepositioneerd als een gezamenlijke verantwoordelijkheid van het Rijk, gemeenten, jeugdhulpbranches en cliëntorganisaties, met landelijke speerpunten, maar ook met een accent op regionale ontwikkeling. Veel aanbevelingen uit de evaluatie zijn geland in het programma Zorg voor de Jeugd of andere voornemens van het kabinet.

Het is afwachten wat de resultaten van de gezamenlijke inspanningen zullen zijn. De transformatie blijft een ingewikkeld en 'langzaam' proces. Wij denken dat het goed is om daar met enige regelmaat en onafhankelijk 'de thermometer in te steken'. Als voe-

\footnotetext{
${ }^{1}$ Zoals de vierde jaarrapportage van de Transitie Autoriteit Jeugd (met als titel Tussen droom en daad, op weg naar een volwassen jeugdstelsel), de opbrengsten van de enquête die vijftien beroepsorganisaties hebben laten uitvoeren onder professionals en de diverse reacties op de eerste evaluatie.
}

ding voor de dialoog tussen de partners over de voortgang. 'Doen wij het samen beter?' is dan een gepaste vraagstelling. Een probleem daarbij is dat de transformatiedoelen abstract zijn geformuleerd en daarmee lastig te hanteren zijn. Cijfers alleen, over de aard van de zorg en de gewenste verschuiving daarbinnen, zeggen daarvoor te weinig.

Het kan helpen om de transformatiedoelen wat meer te operationaliseren. Een aanknopingspunt daarvoor vormen de aanbevelingen van de evaluatie. Die zijn tot stand gekomen tijdens het onderzoek en uitgebreid besproken in de begeleidingscommissie van het onderzoek. Deze aanbevelingen zijn te beschouwen als kritische succesfactoren voor de transformatie. Hieronder hebben we ze als vragen geformuleerd. Met dit soort vragen zijn we beter in staat het gesprek over de transformatie, en ook eventuele volgende evaluaties, te faciliteren. Op landelijk, regionaal en lokaal niveau, in aanvulling op cijfermatige analyses.

Over de inhoud zouden de partners zich de volgende vragen kunnen stellen:

1. Wat vinden burgers van de informatievoorziening over en de toegang tot passende hulp? Is te zien dat daar sprake is van ontwikkeling?

2. Zien we in de uitvoering goede verbindingen ontstaan tussen de relevante domeinen, in het bijzonder voor kwetsbare groepen voor wie het principe van 1 Gezin 1 Plan vooral van belang is?

3. Verbetert de samenwerking tussen vrijwillige hulp en het gedwongen kader, en lukt het om daarbinnen het grijze gebied van drang op een zorgvuldige, transparante manier uit te voeren?

4. Welke visies zijn er op wat passende zorg is voor de uiteenlopende vragen en noden van jeugdigen en gezinnen, en worden die in het professionele veld gedeeld?

Interessante vragen over het proces zijn:

1. Is er in de vrij toegankelijke jeugdhulp een ontwikkeling te zien richting meer eenduidigheid qua manier van werken, en is er een gedeelde visie op de kwaliteit daarvan, zowel in de samenwerking binnen het sociale domein als met de specialistische hulp?

2. Hoe geven gemeenten invulling aan het sturen op en beoordelen van de kwaliteit van de jeugdhulp, en zijn daarin gemeenschappelijke trends in te ontdekken?

3. Lukt het om de administratieve lasten terug te dringen en ervaren professionals hierdoor meer ruimte om hun kerntaak, goede hulp op maat, uit te voeren?

4. Welke ontwikkelingen zien we in het gebruik van het juridische instrumentarium voor de rechtswaarborgen van jeugdigen en gezinnen, en zijn die passend voor het sociale domein? 
Mocht het over enige jaren tot een volgende evaluatie komen, waar wij wel voorstander van zijn, dan hebben we hiermee ook al bouwstenen aangedragen voor de onderzoeksvraagstelling.

We adviseren om de verschillende inhoudelijke perspectieven blijvend in beeld te brengen en onderling te confronteren, zowel inhoudelijk als methodisch. Het heeft ons in de evaluatie geholpen om de herkenbaarheid van de uitkomsten voor de verschillende belanghebbenden te vergroten en om de complexiteit over het voetlicht te brengen. De inhoudelijke expertise op de verschillende aspecten waren ook in het onderzoeksteam vertegenwoordigd. Dat leidde intern soms tot scherpe discussies, maar vooral tot een betere analyse die heeft bijgedragen aan de impact van het onderzoek.

In de evaluatie hebben wij de decentralisatie van taken en bevoegdheden naar de gemeenten als uitgangspunt genomen. Dat was ook de opdracht. De aanbevelingen richten zich grotendeels op de manier waarop gemeenten en partners verder invulling kunnen geven aan de transformatie. Maar op basis van de evaluatie komen ook vraagstukken naar boven die mogelijk (beter) gezamenlijk (op landelijk niveau) kunnen worden opgepakt, zoals eenduidige kwaliteitsindicatoren en een gedeelde inhoudelijke visie op passende hulp. Over de manier waarop dat gedaan moet worden en wie daarin welke rol zou moeten hebben bestaat nog geen eenduidig beeld. Dat is een kwestie die nog wel aandacht verdient.

Tot slot is het aan te bevelen om de samenhang tussen de Jeugdwet met andere relevante wettelijke kaders beter te bekijken. De eerste evaluatie bood weinig zicht op de vraag of de wettelijke kaders van de jeugdbescherming en de jeugdreclassering voldoende op elkaar aansluiten om de praktijk effectiever te maken. Dan zou er ook gekeken moeten worden naar de uitwerking van de Wmo 2015, de Participatiewet en de Wet op het Passend Onderwijs op de doelen van de Jeugdwet.

Dankbetuiging Met dank aan Kirsty Wilson (Sociaal en Cultureel Planbureau) voor het schrijven van het Engelse abstract.

\section{Literatuur}

1. Staatsblad. Wet van 1 maart 2014 inzake regels over de gemeentelijke verantwoordelijkheid voor preventie, ondersteuning, hulp en zorg aan jeugdigen en ouders bij opgroei-en opvoedingsproblemen, psychische problemen en stoornissen (Jeugdwet). Staatsblad van het Koninkrijk der Nederlanden, 105, 14 maart 2014. 2014.

2. TK. Memorie van toelichting bij de Jeugdwet. Tweede Kamer, vergaderjaar 2012/2013, 1 juli2013. 2013.

3. Friele RD, Bruning MR, Bastiaanssen ILW, et al. Eerste evaluatie van de Jeugdwet: na de transitie nu de transformatie. Den Haag: ZonMw; 2018.

4. Toezicht Sociaal Domein, Samenwerkend Toezicht Jeugd. Eindrapport Veilig Thuis van IJZ/IGZ. Den Haag: Toezicht Sociaal Domein, Samenwerkend Toezicht Jeugd; 2017.

5. Transitie Autoriteit Jeugd. Zorgen voor de Jeugd. Derde Jaarrapportage. Den Haag: TransitieAutoriteit Jeugd;2017.

6. Centraal Bureau voor de Statistiek. Jeugdhulp eerste half jaar 2017. Den Haag, Heerlen, Bonaire: CBS; 2017. 